\title{
Beyond the Vows of Distance: The Relationship-Formation of Newly-Wed Couples, A Phenomenology
}

\author{
Evelyn S. Mariñas, EdD ${ }^{1}$, Hildegard Anne S. Alimurong ${ }^{2}$, Gwyn Steffani G. Maningo ${ }^{3}$, Seth Zackari P. \\ Balde $^{4}$, Ramella Glen G. Dinglasan ${ }^{5}$, Gavin Mysjah C. Villegas ${ }^{6}$, Gerone Philip E. Escobedo ${ }^{7}$ \\ ${ }^{1}$ Philippine School Doha, Doha, Qatar \\ ${ }^{2}$ Research Development, Accreditation and Publication Office, PSD, Doha, Qatar \\ ${ }^{3}$ Research Capstone Project, PSD, Doha, Qatar
}

\begin{abstract}
Background: Long Distance Relationship (LDR) describes the physical geography of the partners and has been a typical occurrence in today's world. The study emphasizes that being separated, especially right after marriage, will either make or break the established bond between spouses due to the distance serving as an obstacle in their must-be adjustment period. Methods: A phenomenological research was utilized in this qualitative study to understand the everyday difficulties faced by newly-wed couples who are currently in a long-distance relationship, relative to the central question: "How do newly-wed couples handle their relationship after living separately brought about by working abroad of a partner?". Data were gathered using a twenty-five semi-structured interview and were analyzed using an inductive approach for thematization. Findings: Findings have shown the common difficulties such as emotional loneliness, misunderstandings, and lack of physical presence, lack of trust, and infidelity are faced by the interviewed spouses. Conclusion: Long-distance couples make not break their relationship by facing everyday difficulties together through marital compromise, personal development, communicative atonement, and digital connectivity. Recommendation: The study recommends to not engage in a long-distance relationship in the early stages of marriages. Moreover, to fill in the literature gap, this study recommends a better understanding of perspectives by interviewing both spouses and increasing the number of respondents with varying sexualities and nationalities.
\end{abstract}

Keywords: Long-distance Relationship; Newly-wed couples; Relationship-formation; Relationship Struggles; Communication

\section{Introduction}

Relationships have always been a necessity for all social beings. Bonds nourish and train one's mental health, allowing the mind to reach a wide range of emotions, thoughts, and feelings. As defined by Kansky (2018), a relationship is a pervasive bond which combines the concepts of intimacy, commitment, and passion.

People visualize relationships to be joyous as they are together physically. However, in reality, there are instances wherein a couple celebrates their love from a distance. Having a long-distance relationship does not conquer the idea of love. The separation does not define the bond's strength, but rather, it is trust and open communication.

Relationships may reach the stage of life-long commitment or marriage. By definition, it is the "formally recognized legal union of two partners" (Oxford Languages). It has always been one of the most significant and momentous events in people's lives and an essential component of their lives. Furthermore, it is the highest and the most important institution in society due to its life-long commitment being built on trust, 
love, tolerance, and unconditional support. However, there are some newly-wed couples who will inevitably commit to a long-distance relationship because of personal issues such as occupation or pursuing higher education (The Lasting Crew, n.d.).

Furthermore, a couple being distanced for long periods of time is an event that both partners will find difficult to cope up with. It will either test the limits of the relationship or eventually become the focal point of the relationship's downfall. Kibin (2017) stated that one of the possible reasons for distanced relationships is the pursuit of higher education and careers. It is crucial to set terms and rules before the separation. Issues can present themselves if the other partner opens themselves to others, while the other makes sacrifices for their relationship.

Moreover, Singh (2019) discussed possible factors that are essential in a long-distance relationship; the most notable is seeing the relationship as an opportunity to grow for both partners and improving and/or maintaining independence by exploring one's identity, especially the likes and dislikes (Raypole \& Litner, 2021; Baldt \& Ulrike, 2020). Carmina (2021) reiterated that spouses one must first save oneself, in order to recognize the opportunity to save a relationship. The second factor is keeping a goal of building the relationship even more. Ascertain that the couple's life together does not come to a halt, even if they are separated by a great distance. Couples in long distance relationships reportedly show more love for their partners, with the extra dedication they put into their relationship to narrow the gap of the physical distance (Engle \& Johnson, 2020).Last is communication or "an act that allows partners to explain their experiences, needs, and wants to each other" (Scott, 2020).

Conflicts are inevitable in a relationship, but it should be addressed directly. However, confronting conflicts in LDRs is different. Smith (2018) reported that LDR couples would commence their conflict online before engaging face-to-face to alert their impending dispute. To account for the lack of physical interaction, couples use different technology-based channels such as video, voice, and text applications to communicate with each other to alleviate the misunderstandings and problems in their relationship (Sotto-Herrera, 2018; Kelpinski, 2019). Couples should learn proper effective communication for their relationship to work. They cannot physically check each other, and poor communication can lead to misunderstandings that can escalate into distrust.

Due to the COVID-19 pandemic, the data used in this study was gathered through an online interview. This study examines the lived experiences of long-distanced newly-wed couples, capturing their developing feelings and emotions, and their adaptations to the relationship. However, the impacts of a longdistance relationship on other family members, relatives, and close friends that are affiliated with either of the two individuals involved, have not yet been further researched by other studies. While a couple in a longdistance relationship is significantly affected, one cannot rule out the fact that other relatives and relations are affected or can affect the couple directly.

Based on the verbal musings of the chosen participants, 4 themes were created. These are (1) Adverse Circumstances, which has the sub themes of Time Contrasts, Attitudinal Incompatibilities, and Familial Upbringings; (2) Initial Adjustment, which has the sub themes of Marital Compromise, In-laws Relations, and Financial Literacy; (3) Connectivity Reinforcements, which has the sub themes of Relational Partakings, Communicative Atonements, and Digital Approach; and (4) Psychological Outcomes, which has the sub themes of Personal Development, Reticent Considerations, and Yearning Presences.

The study analyzes the lived experiences of newly-weds in a long-distance relationship. It aims to answer the central question: "How do newly-wed couples handle their relationship after living separately brought about by working abroad of a partner?". Specifically, the researchers want to know the common everyday struggles of the newlyweds. To further understand their lived experiences, the researchers would also want to know how the participants came up with the decision on working separately, how well is the bond 
between the husband and wife, how does the distance affect the both partners emotionally and psychologically, and how do they deal with conflict.

The researchers aim to understand the spouses better through interviews. Thus, this study serves as an educational medium and guide for long-distance newly-wed couples to cope with the difficulties occurring in their current relationship status by rendering them aware of potential adversities and possible solutions that accords with such relationships.

\section{Methods}

\subsection{Research Design}

The present research paper is qualitative and utilizes interviews as the primary source of data collection. Qualitative research "aims to understand the natural setting of different social groups, individuals, and cultures" (McLeod, 2019). It also does not require numerical data but instead interprets the empirical data gathered through interviews. This type of research allows the participants to further discuss the topic in more depth or their own words. Phenomenological research "addresses answers to the why and how of the problem instead of the what" (Irarrazaval, 2020), and this study seeks a more profound understanding of a social phenomenon. The format used for this research paper was IMRaD which stands for Introduction, Methods, Results, and Discussion. This format is frequently used for medical management and natural sciences.

Contrary to social sciences research papers, this format does not require a separate theory chapter. According to SOV \& SKRIV (2020), the IMRaD format is "short, plain, and purely objective. Compared to the Germanic format used priory, this type of research is more brief but comprehensive. It requires displaying much information clearly within a few words. Simple words and statements are often seen in this format; therefore, it must not be decorated and must be bare. Personal opinions and cliché language are avoided due to the formality of a research paper.

A letter of consent was forwarded to the participants to proceed with the interview. After the participants have been allowed to conduct the interview, a set date was given to the researchers to follow. The interview was held through the use of zoom due to the COVID-19 restrictions. At the start of the interview,

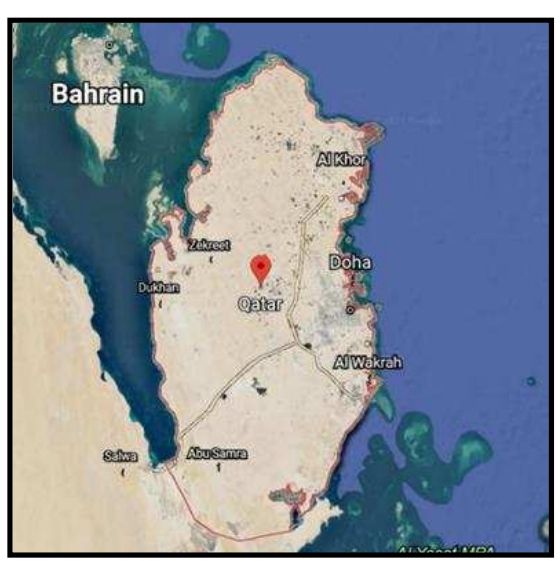

Figure 1: Map of Qatar Source: Google Maps the researchers asked for approval to record the participants' answers. After that, they transcribed the response of the participants with the use of emic-to-etic transcription. Inductive reasoning was applied for the thematization of the responses. It starts with specific observations and measures from the different answers given by the participants in the research. They then began to detect patterns and similarities from the data. It was later used to formulate some tentative hypotheses that could be explored and arranged. Once that was all done, the researchers could finally develop generalized conclusions or theories.

\subsection{Research Locale and Sample}

The study was conducted in Doha, State of Qatar. at Philippine School Doha (PSD), a learning institution established in October 1992. Under the patronage of the Philippine Embassy, its foundation is considered a product of the determination of 
pioneering members of the Filipino community. The school has been continually providing basic education to the growing population of Filipinos in accordance with its transfer to its permanent location in Mesaimeer, catering to more than 4,000 students. It is also widely recognized for its accomplishments on both a national and regional scale. The said location was particularly chosen due to the limitations of the researchers to travel across other countries. This also grants the researchers the convenience to easily facilitate their interviews with the participants, considering that all selected participants are currently residing in Qatar having the same time-zone as the researchers.

The participants who were selected to take part in this study were: (1) either of the spouses of a longdistance, newly-wed couple; and (2) are within 3 years of marriage. The researchers utilized a qualitative purposive sampling technique to determine 7 participants who are appropriate for this study. This sampling method is primarily based on characteristics of a population and the objectives that the study wishes to meet (Crossman, 2020). The participants' insights are believed to be constructive to this study given that they all are newly-wed and have undergone the experience of living apart from their spouses.

\subsection{Data Collection and Ethical Consideration}

This study contains the necessary set of data gathered through a semi-structured interview. Consent forms were validated then given to the participants. The researchers asked the participants' preferred time and date to commence the discussion through the consent letter. The consent form provides the participants with adequate written information allowing an informed decision on participating in the research study. An explanation of the proposed research and the nature of the requested participation was stated (Swarthmore, 2021).

Included in the consent form is the Robofoto, which has the necessary personal information of the participants. A Robofoto is "the demographic sketch of the respondents" (Garcia \& Acosta, 2016). This contains the name, sex, occupation, years married, and years living separately.

The interview was conducted through Zoom, the video-telephone software, and was recorded with consent for further analysis by the researchers. The researchers were each assigned to interview a spouse in a long-distance relationship. Each of the participants was informed beforehand and agreed to participate in the interview. Their participation was voluntary. They were oriented about the procedures of the interview before it commenced. The personal information of participants will remain highly confidential throughout the research. The interview questions were prepared by making three specific questions. Among the specific questions, one was chosen to be the central question. Sub Question and developmental questions were then formed based on the central question.

The researchers then encoded the data for further interpretation using the Emic to Etic format with the participants' responses. Mostowlansky and Rota (2020) described the etic concept as representing aspirations for a scientific, objective approach to the study of culture, while an emic concept as the purpose of understanding the world from the perspectives of one's interlocutors. The concept of emic and etic in this study, where the emic transcription of the interviews are the exact words and sounds uttered by both the participants and interviewers, while the etic transcription of the data is modified and edited better to suit the researcher's requirements for data analysis.

\subsection{Data Analysis}

The researchers used the inductive approach in this qualitative study. Aspers and Corte (2019) defines the research method as an outcome of iterative and systematic processes to capture core facets and enhance understanding of a phenomenon : (1) collecting the audio recordings for the assured understanding of 
the participants' insights on the topic; (2) processing gathered data to further suit the researchers' requirements; (3) transcribing the gathered responses and data to fit perception of the participants' responses; (4) categorizing the similar data, arranging through units, and place the cluster of the themes into the dendrogram; (5) producing a simulacrum which showcases the themes and subthemes based on the dendrogram.

\section{Findings}

Relationships are part of everyday life. It can have different variations depending on the people involved. One of these variations is the long-distance relationship where an intimate commitment is formed between two people who, unlike traditional relationships, are geographically separated from one another. This type of relationship is often viewed as an extreme challenge with unavoidable suffering; however, a strong foundation must be initially established to ensure its success.

In that regard, this phenomenological study explores the four emerging themes concerning the relationship formation of newly married couples who are in a long-distance relationship that led to answer the question: "How do newly-wed couples handle their relationship after living separately brought about by working abroad of a partner?". The question is then further narrowed down to four specific questions, each with their relative developmental questions.

Figure 2 shows the simulacrum focusing on the difficulties of the relationship-formation of the newly-wed couples in their long-distance setting. The struggles revolve around the four major themes namely

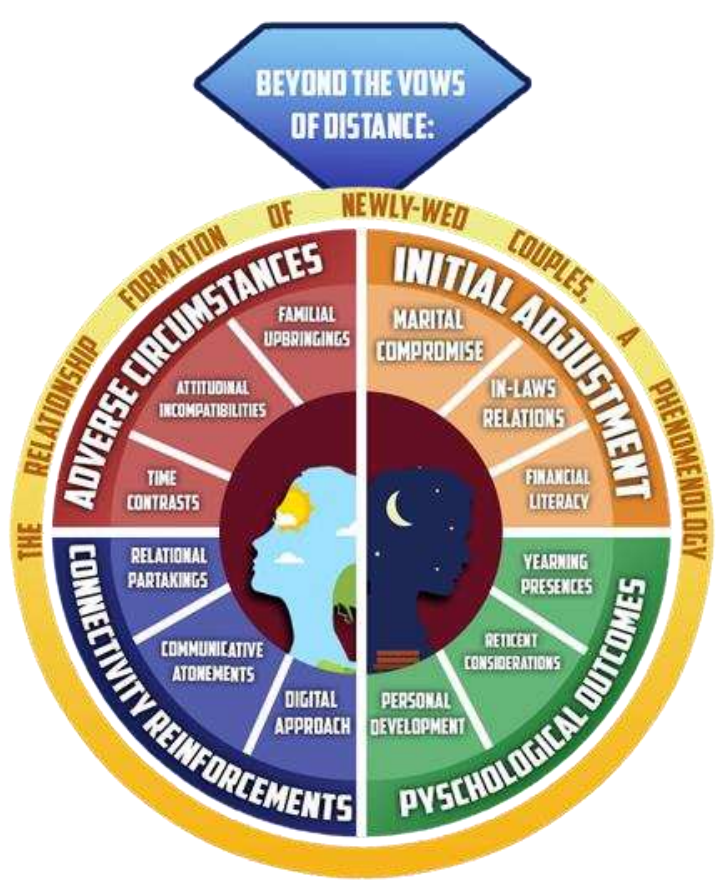

Figure 2: Relationship-formation of the Long-Distanced Newly-wed Couples Simulacrum Adverse Circumstances; emphasizes on the things that the couples find difficult to deal with in their current situation, Initial Adjustments; focuses on their adaptation and transition of to the wedded life, Connectivity Reinforcements; dwells on the medium they used to stay connected, and Psychological Outcomes; discusses the cognitive effects they experienced while being in a long-distance marriage. Each theme represents the significant experiences that the couples have faced when they are living separately. While there are many reasons that lead to long-distance relationships, it is critical to know how their difficulties developed and how they are handled to have an in-depth understanding on the perceptions of long-distance newly-wed couples.

\subsection{Adverse Circumstances}

No relationship is perfect. The first years of marriage are filled with changes and adjustments as the newly-weds adjust to their new roles. However, along with the happiness of finally being married comes the 
ups and downs. Unexpected difficulties are bound to happen, which can either make or break one's bond with each other, thus forming the theme: Adverse Circumstances.

The first subtheme, Time Contrasts, focuses on the spouses' behaviours being limited by time. In long-distance relationships, couples are divided not just by physical distance but also by the passage of time itself, be it their own schedules or time zones. Based on the participants' responses, not only do they have to limit the amount of time they spend with their spouse, but also the doubled effort they have to exert just to see them.

"We communicate every day. Before, we used to converse using Facebook Messenger but, nowadays, you need X-VPN to connect properly so currently we're using IMO. We make it a point to talk every day and we even have schedules. From 12 to 1 am Qatar time, he's going to tell me his What to Do's for that day, and as for me, I'm going to give him a summary of what I have done yesterday. When it's $2 \mathrm{pm}$ to $3 \mathrm{pm}$, we're going to catch up on things we didn't mention earlier on our first schedule. However, due to the pandemic, my schedule has changed. I'm currently taking up 12-hour shifts, so I can't talk to him at dawn. I'll only talk to him during my lunch breaks at 12 noon." (P1)

"I think it would be the time difference. The time zone disparity would make it difficult for me to talk to her since I would just get back home from work here in Qatar but meanwhile, she would still be asleep in the Philippines." (P4)

Attitudes, behaviours, and principles are abstract things that everyone possesses. Each varies from person to person, either positive or negative. In marriage or relationships in general, there exists the honeymoon stage where everything seems carefree and joyous. The second subtheme, Attitudinal Incompatibilities, showcases the perceptions of the participants regarding the flaws and differences between them and their spouses.

"At the start of our marriage, I found it difficult to understand his behaviour at home because I am adventurous, but he likes to stay at home. So, if I want to go outside and he doesn't, I will just go alone." (P2)

"It is difficult to understand each other's attitude, own beliefs, and not being on the same boat." (P6)

"Though I find it hard because of her attitude, I would always try to talk to her whenever any of us has any complications." (P4)

The last subtheme, Familial Upbringing, emphasizes on the participants' family backgrounds having an effect on their relationship. This usually leads to some of their misunderstandings as their partners struggle to comprehend their standard of norms that exist within their family.

"I don't like the idea that we're going to live together with his or my family. I know that we will have arguments because we're still two different people with different upbringings. " (P1)

"I grew up in a strong family, that's why I express myself strongly and aggressively but with no bad intentions. He gets irritated sometimes because he thinks I'm yelling at him but actually that's not the case." (P7) 
Conflicts within relationships are normal. It is an inevitable part of any marriage that plays a role in whether the relationship ends or continues. With being in a long-distance relationship in their equation, resolving conflicts has become more difficult. Fortunately, having relationship hurdles that can vary from inlaws and differing opinions from time to time can help couples formulate strategies that will prevent them from happening again in the future or at the very least, make resolving similar problems much easier to handle.

\subsection{Initial Adjustment}

There are future problems that can be experienced by the married couple like difficulty in understanding their significant other's attitude, difficulty in dealing with their significant other's in-laws, and difficulty in their overall attitude towards the relationship. Couples have to adapt to countless situations thus entering an adjustment period between the couples. They have to make more effort in the start of their relationship because of the great physical distance between them, therefore the theme is called Initial Adjustments. The theme focuses on the process it takes for the couples to adjust into a married life.

The first sub-theme, Marital Compromise, discusses the ability of couples to reach an agreement in order to solve problems in their relationship in a long-distance setting. There are conflicts in relationships that have a multitude of ways to resolve with the coordination from both partners. According to this study's respondents, they mostly communicate to solve their issues:

"If I have personal issues with him, instead of voicing them out, I'd rather send him a message on Facebook or whatever social media; or I'd ask him to go out with me to the mall. Of course, you know, somehow, I need to learn to compromise because if I keep thinking about it, my husband and I would fight often." (PI)

"Communication is key for long-distance couples. We try to manage our time by communicating before we sleep or throughout the day." (P3)

"One of the difficulties we face is when one or both gets mad at each other through some misunderstanding, but through communication, you will be able to get along." (P6)

The couples communicate to their partners about their problems to create a compromise to find a solution. Clear communication is essential in resolving marital conflicts to prevent further damage in the relationship. However, some respondents have stated that they have personal issues with their partners that they resolved by not voicing them out. They use other methods of communication like written communication.

The second sub-theme, In-laws Relations, tackles the problems that the couples have with each other's extended family and their in-laws. Families will not always agree with one another which can lead to difficulties in the household. The participants experience difficulty in adjusting to their significant other's family, mostly due to not being able to voice their concerns as cited below:

"After we got married, we stayed at his family's house and it was difficult for me to make an adjustment to his family as his wife because I have to get along with his siblings and mother. I can't really voice-out my concern that well because I fear that I would be disapproved of by his family. ” (P1)

Fortunately, as time went by, they seem to be well affiliated now and are in good terms with their spouse's families: 
"One of the most helpful outside factors is the family on both sides. My husband is not really updating me about his whereabouts, so his family updates me instead. Aside from our family, we have our friends who are of great help in the maintenance of our relationship. They're always giving us two encouragement." (Pl)

"The outside factors are the family that he has here. Bonding with them feels like I am spending time with him. His first cousins check on me when they know that my husband and I are not okay." (P2)

The last sub-theme, Financial Literacy, talks about the knowledge the couples have to make effective decisions with their financial resources. Having a clear understanding and sufficient knowledge of financial facets is essential to having a stable marriage and future.

“They're not thoughts, they're feelings. I keep thinking about when he will come here to Qatar. I felt homesick for the first year I came here in Qatar back in 2015, and I became even more homesick when we got married. We're not boyfriend and girlfriend anymore. God has fortified our relationship. My thought at that time is that God is giving me time to be financially ready by the time he comes here." (P1)

"If there is a problem between the two of us, we try to work it out, for example if we have financial problems, we try to help each other. If the problem is beyond us, we ask for help from other people. Although we assure each other that we are always there for each other. If I have a problem, she is the first person I talk to because my wife is my confidant." (P3)

Starting a relationship will have conflicts along the way because of the couple's adjustments with each other. Couples will need to compromise to solve their problems or the fight would prolong and the effect will affect the relationship in a negative manner. Inserting oneself in their significant other's family will have some adjustment in the household, and the transition period can be difficult for both groups. The couples should possess financial knowledge to have stability in their relationship. Common financial literacy skills such as budgeting can help the couples have a stable relationship.

\subsection{Connectivity Reinforcements}

In contrast to its local correlative, long-distance relationships require much more conscious thought and consideration to maintain the bond between the newly-weds. Hence the theme being termed as "Connectivity Reinforcements." Such pertains to the couples engaging in recreational and mutual activities together, in hopes of relieving the sentiments brought about by their distances.

Encompassed under the theme expresses the participant's ingenious utilization of social networking sites and communication technologies to communicate with their spouses. Accordingly, the sub theme is termed as Digital Media, a significant facet in today's world of rapid globalization and technological advancements. As stated:

"We communicate every day, sparingly throughout the day and especially at night time. Also during weekends when we do not have classes. WhatsApp, FaceTime and Messenger are what we use to communicate." (P3)

"LDR couples nowadays are very lucky with the advantage of technology and the rise of easier access to connecting with loved ones that are far away, not unlike before where they had to wait a month to receive or reply. We share some pictures and videos with each other, especially our daughter's for him to see her growth." (P7) 
Essentially, the role of digital media sites and networks is paramount particularly to geographically separated couples. In which the effectiveness of these applications arises in much more feasible communicative discourse, enabling these couples to express their communicative and relational necessities through the mediums of digital processes accorded by real-time and co-participative efforts. Herewith, longdistance couples perceive beneficial reassurance by each other's gestures of apprising thus creating a relational environment to the likeness of being geographically together.

In correlation to its use for recreational pastimes, social networking sites could also serve as a medium for spouses to address conflicts rooted from their distantial misunderstandings. This notion comprises the second sub theme titled Communicative Atonements. As stated by the participants:

"Misunderstandings will happen especially because you are not able to talk to each other, but with the advent of science and technology, it opens new ways. It became difficult for me because of the pandemic, yet having constant communication, honesty, and trust helped. With the power of prayer and hope, we will be together soon." (P3)

"Though I find it hard because of her attitude, I would always try to talk to her whenever any of us has any complications.” (P4)

Besides communicating remotely through social networking sites, long-distanced spouses also go the extra mile to perpetuate and strengthen their relationship. As designated in the last subtheme: Relational Partakings. These efforts include expressing marital affection through surprise visits or considering modes to make one's presence known to each other through familial accommodations. As quoted by the participants:

"I love surprises. When it's already our anniversary, I will talk to his sister, then I will ask her a favour to buy and prepare something special for him. As for him, he bluffed about not having a surprise. When I got home from work, I saw a huge bouquet of flowers and my friends had someone draw a charcoal painting of one of our wedding photos. And another thing, I'm an impulsive buyer, so whenever I want something, I have to tell him first. Not for permission, but somehow to control my spendings. On the day of our anniversary, I received a call saying that I have to buy the bangle I that I have been eyeing and I don't have to worry about the deposit because he'll cover that for me. Those are his surprises. When it comes to birthdays, I'll do the same also. I'll make it a point that he'll feel special." (P1)

"During anniversaries, I go back to the Philippines (before the pandemic). In birthdays, I planned a surprise for him through the help of my friends in the Philippines and he does the same with his friends in Qatar." (P2)

Despite their geographical differences, the couples demonstrate relational commitment owing to their exceeded efforts. These partakings signifies that momentous celebrations and marital milestones do not deem impossible yet require advanced and well-considered planning.

Certainly, long-distance relationships consist of its distantial adversities - necessitating both partners to establish and manage their routines on the account of keeping their communications open and clear. However, this contemporary age has proven that such relationships are not inherently difficult to manoeuvre. Due to the rise of recent digital media, couples are endowed with accessible and varied utilities for concurrent communication - preluding the notion of geography as non-existent. Thus, rather than perceiving it as an adverse endeavour, couples see such as an enduring provocation that better sustains a young and growing relationship; accordingly, creating greater admiration for one another. 


\subsection{Psychological Outcomes}

A relationship holds numerous challenges, and each pair copes with these trials differently. Based on our findings, the distant factor influenced the longing feeling for their respective partner, and discovered that the participants exhibited bouts of isolation and loneliness. The participants have also notably expressed their independence due to long-distance. These observations lead the researchers to believe that the participant's overall outlook into their relationship adapted/changed to cope with the separation. Thus, the theme is named Psychological Outcomes, and talks about the emotional and mental effects that manifest between partners.

Misunderstandings and challenges in a bond between spouses lead to psychological effects. These hurdles double the amount considering the distant factor. Moreover, this theme focuses on the psychological effects the participants have experienced while in a long-distance relationship.

The impact of distance between spouses, and the lack of physical intimacy, provoked a desire to be with each other physically. Most respondents use communication to handle and establish trust between their partners. Furthermore, the first sub-theme is Yearning Presence. As the couples live their separate lives, the researchers discovered a longing feeling for their spouses most of the time.

"Even before we got married, we're not really physically intimate because we respect each other. But after we got married, I have this feeling that I want to be physically intimate but he's not here. I miss him." (Pl)

"Not being with your wife is indeed a lonely experience, the pangs of loneliness are really evident. What I do to keep my mind off of that loneliness is through exercising, playing games, and going out. However, I am a stay-at-home person and I would rather talk to my wife than go to the mall." (P3)

Having been separated from your spouse while being married evidently shows a longing affection for their partners. However, they are willing to go through the hurdles of a long-distance relationship for their future. All will be worth it to have that moment of being with each other physically. The couples cope with this struggle by having constant communication. Most of them firmly believe that having regular contact with their partners is fundamental. Distractions, such as going outside and recreational activities, also help to prevent the desire to see each other.

Obstacles are always present in a relationship. Being separated from their spouse caused the participants to show restraint to avoid a quarrel, as resolving conflicts in their current situation is more challenging than being physically together. Not being able to communicate face-to-face with their partners led the participants to avoid bringing up arguments. Instead, they chose to look for other ways to solve a problem to prevent misunderstandings from taking place. Hence, the second sub-theme is Reticent Considerations.

"I'd rather keep my mouth shut rather than voicing them out because I might say unnecessary things because of my emotional instability." (P1)

"If he does not understand my difficulties, I just stay silent. Sometimes, I'll just go outside to take a breather so that I cannot say hurtful things to him." (P2)

However, it is difficult to hold back against big inconveniences. Rather than keeping quiet, one participant stood out as they chose to confront their spouse regarding their infidelity. 
"Our relationship weakened through time; we have not been okay since last year. He cheated on me while I was abroad, I forgave him, but he lost my trust. Ever since then, we keep on fighting until we end things." (P2)

Lastly, the third sub-theme is Personal Growth. The long-distance relationship allows both spouses to improve individually, as they learn to adapt to the distance between them and their partner while also being able to engage in recreational activities that are well out of their comfort zone as a way to cope with said distance and thus, spend more time with themselves.

"It's not every day that I feel lonely or alone; there are triggering factors. Such triggers are occasions that we should have been together like this Christmas and New Year. It saddens me, but whenever I feel sad, I'll always watch our same-day edit. I'll reminisce about the vows we've given to each other. I've always said to myself that I had this super happy moment that I have to maintain. Okay, I'm jealous of the couples I see who are celebrating special occasions together. I'll send him a message saying "I'm sad today", and then whenever he's available, he'll comfort me. He's going to uplift me again. He's going to remind me that we'll be together soon. There would no longer be Christmases, New Years, birthdays, and anniversaries that we're not together." (PI)

"I'd feel lonely again whenever I see couples on Facebook together, but then I remember I have my family and friends. They're the first ones we know down the long road and they're the best distraction. I hang out with them, enjoy being together. I also encourage my husband to do the same while waiting for us to be together. " (P7)

It became a way to keep the spouses preoccupied amidst the distance between both partners. Couples developed independently by learning how to cope with overwhelming emotions. Examples of these strategies are exercising, going out with friends, and spending time with their families.

"The distance strengthened us in our perspective. It taught us a lot of things like trust by refraining from any type of temptations. We watch movies at our own time just to cope up with the times we go to the cinema together. This makes our bond unique. We've also learned to mature more individually due to the distance. We experienced being weakened by it because we've experienced being in an LDR for 4 years, but we learned how to resolve it through time. Hence why we're more solid as a couple because of the distance we currently have." (P1)

"As much as possible since we are in a long-distance relationship, we try to avoid misunderstandings. But sometimes it is inevitable, what I do is even though I am not at fault, I say sorry. We do not let pride get in the way because we are not kids anymore to fight over petty things. " (P3)

To conclude, the theme highlights the psychological impact both individuals in a long-distance relationship encounter, and the methods and factors that help in the managing of these impactful emotions. The distance between the partners was not the only factor contributing to the psychological outcome, as stated in the responses of said participants, but it also takes into account the already pre-existing psychological and emotional aspects that are being tested as they are in a distanced relationship. 


\section{Discussion}

Entering a relationship means numerous sacrifices, compromises, and understandings must be made. They must understand that if they choose to work long distance for both careers, there will be challenges and they must schedule time with one another. Long-distance relationships, as defined in this study, refers to spouses separated by geography. Computer mediated romantic relationships have transformed the way scholars look at some aspects of romantic partnerships as more people communicate with their romantic partners online and may discover that their knight in shining armor lives far away (England, 2018). However, maintaining such a relationship is not easy as there are several setbacks and difficult moments in the process of making it work.

Moreover, a growing number of couples are opting to commit to a long-distance relationship as a result of cultural reasons such as advancements in transportation and communications technology, pursuit of higher education, and career responsibilities (Stafford, 2006; as cited by Lee, 2018). The interpersonal relationship of the husband and wife can be maintained not only in close proximity but also at a distance as well (Suminar and Skaddi, 2018). With communication technologies being one of the important elements in interpersonal relationships, intimacy has been encouraged in long-distance relationships, allowing highly skilled migrants to keep in touch with family members (Gonzales-Ramos, 2020; Roberta, Schiavio, \& Biasutti, 2020).

\subsection{Adverse Circumstances}

From the intriguing insights and reflection of the selected newly-wed spouses who are currently in a long-distance relationship, the findings of this phenomenological study have clearly indicated that unexpected events are bound to happen within the first few months or years of marriage, even while living separately. Conflicts are one of the features of relationships that is inevitable. In general, newly married couples do not have sufficient preparation for their future parenting as new parents-to-be (Sutrimo, 2018). Moreover, there are also internal stressors caused by troubles within the partnership, usually personality or attitudinal issues (Awonuga, 2020). Typically, they involve issues with one's spouse or the LDR itself. They must learn how to cope with the lack of knowledge, adjustment, and understanding as they transition to a new phase of their life while living separately from each other, else challenges may appear. Aside from those, strong commitment is also required since the quality of a long-distance marriage relationship is influenced by the dedication of the spouse (Eka Fhitrah \& Afdal, 2021).

The ability to deal with disagreement amongst couples in long-distance relationships is critical as they have less time to be with each other, let alone still adjusting to their newly-wedded life. They sometimes confront difficulties in maintaining their relationship across distance because computer-mediated communication systems often only allow a limited range of relationship maintenance practices. (Yang, Neustaedter, \& Schiphorst, 2018).

Regarding the first subtheme, "Time Constraints", Acedera and Yang (2019) defined time as something universal, uniform, and absolute due to the movements of the sun being objectively and scientifically determined. Time differences lead to the formation of negative emotions such as suspicion and heightened misunderstanding (Yang, 2021). They are, however, already accepted as a fact of life and a circumstance in this kind of relationship (Yang et al., 2018), though they should still be prepared as they will face a variety of challenges, including inability to communicate in person, unmet inner needs, and a sense of inadequacy when one partner is not always present, especially at crucial moments (Wijayanti, 2021). It is inevitable that the couples who are in the status of long-distance relationship would have to deal with the time 
difference, but they formulated schedules to keep the connection as exhibited. It is one of the responsibilities of the couples to update one another to make up for the time they have lost when they are still living together.

Secondly, in the second subtheme, Attitudinal Incompatibilities, attitude is a separate notion that plays a significant role in distinguishing individual characteristics in social psychology (Kurniasari, 2021). Some people may not always find the perfect match to their mindsets and principles, but they would, however, would often find someone who can handle them. Non-proximal couples are on their 'best behavior,' allowing idealization to continue rather than getting to know their spouse on a deeper, more intimate level (Craft, 2018). Although newly-wedded, the participants have expressed that they still find incongruence in their personalities and that the distance between them made it difficult for them to understand each other. A decrease in love, affection, and responsiveness, as well as an increase in ambivalence with the first few years of marriage can predict divorce after 13 years (Niehuis et al., 2015; as cited by Stritof, 2021).

Lastly, regarding the last subtheme, "Familial Upbringings", family interactions create long shadows, especially when we're young, and they penetrate our mind deeply (Raheja, 2021). Aside from getting to know their partner as someone they have a matrimonial contract with, they are adjusting to each other's family as well. Things normal within the person's familial circle may seem strange to others, and that may lead to some misunderstandings and possibly conflict to some newly-wed couples as showcased. Personality, fundamental values or views, age, gender, educational qualifications of the partners, and patterns they observed as children in their families of origin all influence how they approach marriage life adjustment challenges (Johari, Singh, \& Mehra, 2020).

Perfect marriage may be the hope of many, especially by newlyweds. It can fulfil the desires of giving and receiving affection, warmth, and friendship (Mijilputri, 2015; as cited by Faradina et al., 2020), and with these three in balance, it can lead to a successful marriage (Wulan \& Chotimah, 2017). Despite the ubiquity of conflicts within the first years of marriage and while being in a long-distance relationship, they are seen as trials to determine their willingness to stay committed. Furthermore, distance may be a unique and additional source of stress in relationships, leading to a preference for specific relationship methods in terms of how people interact in these relationships.

\subsection{Initial Adjustments}

Every couple has to experience adjustment periods in their relationships. They both have to work together for the relationship to work. A good compromise requires a feeling of trust and security when making the decision. The couple needs to be in complete understanding within each other to resolve a conflict and to avoid aggravating another problem. In marital conflict, compromising is one of the five coping strategies in resolving conflicts in couples, these being competing, collaborating, avoiding, and accommodating (Tasew, 2021). However, there are unhealthy compromises such as the other partner asserting their authority over their significant other. The newlyweds do not only adjust to each other, but also to their other partners' family. According to Benyamin, et al. (2018), the major conflict that comes with each other's extended family and in-laws is living up to the expectations. They added that the source of the conflict is miscommunication. The couple should communicate with their parents and family to lessen the prejudice or negative connotation that the extended family and in-laws have. Financial literacy is important to married couples because it equips them with the knowledge and skills to manage money effectively. Sawai et al. (2018) concluded that budgeting is essential for newlyweds to avoid financial strain, further defining it as a financial phenomenon that occurs when a person's expenses exceed their income. They later added that a higher financial strain contributes to a decreasing marital satisfaction.

Initial adjustments are difficult since it is a change in situations or circumstances. Godana (2019) stated that long-term marriages are determined by the initial adjustments during the first three to five years of 
marriage. Initial adjustments also emphasize the factors that influence the marital quality during the first few years of marriage. The author also added that factors such as financial literacy, marital compromise, and familial hurdles are prominent in the adaptive process like how couples communicate, solve marital problems, and handle stressful situations.

In conclusion, there will always be conflicts in the adjustment period. Newlyweds couples should excel in adaptive relationship processes like communication and conflict management to have marital satisfaction (Monk et al., 2020). Rajput (2017) states that having a good marital adjustment and anxieties living apart can still lead to a happy and contented marriage. Long-distance newlyweds can still have a functional marriage despite the physical barrier that exists in the relationship.

\subsection{Connectivity Reinforcement}

It can be reasonably inferred that couples essentially develop strategies to sustain their relationship quality - albeit being physically and geographically separated. As surmised in a journal article by Wei-Chi and Hassenzahl (2020), relational maintenance renders as a distinguishing construct of long-distance relationships. Furthermore, such partakings essentially require responsive interaction. Though a counterintuitive notion in long-distance relationships contexts, more responsive interactions among long-distance couples accounts for greater connectivity satisfaction.

A distinct and evident approach is the particular use of social networking sites for remote communications. The previous decade defined the significance of social networking sites in its expansive and worldwide evolution. According to a study by Holtzman et al. (2020), the widespread adaptation of smartphones enables couples to contact their spouses from virtually anywhere, which is especially crucial in long-distance relationships compared to geographically close relationships. Herewith, couples can exchange various aspects of their daily lives in real time, from the most mundane to the most salient.

Notably, various technology mediated communications also account for varied levels of satisfaction in long distance relationships. A study by Hampton et al. (2018), comparing various categories of social networking sites used in long-distance relationships, revealed that video call platforms - such as skype and zoom - are optimal social networking sites for greater relationship satisfaction of long-distance couples. Such finding deduces that video calling platforms offer more advantageous communicative variables that other social networking platforms lack: visual and audio cues.

Through time couples long for their partners, especially with the lack of physical intimacy. With couples getting used to the new ways of strengthening their relationship and spending more time with each other through connectivity. Caroll (2020) stated that through listening, people can remind their partners that they are still there, which is always about the other person and never about us. With the notion of constant interaction and reassurance, the physical distance of spouses does not adhere to the distance of the endearment of the couple. Being an active listener serves the purpose of attaining the trust of your spouse and helping you to understand their situations. Comprises both a desire to comprehend as well as to offer support and empathy to your situation.

\subsection{Psychological Outcomes}

Any relationship of any kind and nature will cause psychological changes and influences manifest between those involved. Long-distance relationships create unique challenges for couples, potentially impacting both and individual well-being (Belus et al., 2018). When partners are together, they experience changes in their behaviour and mannerisms. Those changes amplify when factors such as distance separate them, as they consider the overall condition of their significant other in the long-distance relationship. 
Feelings of guilt and discomfort are very likely to happen, but this feeling gradually erodes with routine activities, especially for couples who become grantees (Suminar \& Kaddi, 2018). In a long-distance relationship, anxiety and worries heighten as couples lack physical reach. Furthermore, a yearning feeling took place due to the physical detachment, but as stated earlier, the continued performing of routine activities lessened these feelings.

The separation gave the couples a chance to gain personal development through spending time with other relevant matters. Gatherings with their respective families and friends were done in their immediate vicinity. Having this time also gave them a reason to do other activities such as listening to music, reading books, and playing video games.

Belus (2018) stated that it is important to understand the efforts that long-distance couples make to stay engaged. Communication and quality time serve as a way to lessen strong emotions that may further put more distance between both partners. Patience is seen and practiced in both partners to create a safe space in their relationship. In times of disputes, partners tend to keep quiet to evade the arguments from escalating. However, honesty is a valued part of a long-distance relationship to work.

\section{Conclusion}

Relationships are constantly evolving. Given such circumstances, some couples would not be able to spend the first few months or years physically together but at that point the majority of long-distance couples have formed a unique bond between each other, given their commitment and willingness to stay in the relationship. Due to logistical concerns that young couples encounter, society has become more accepting of the hurdles and difficulties that come with long-distance dating (Jiang \& Hancock, 2013; as cited by Bratcher, 2017). Unfortunately, the media usually exclusively portrays LDRs in a negative light, which may not fully reflect the genuine lived experience of an LDR (Goldsmith \& Byers, 2018).

This study observed and evaluated the effects that take place in a long-distance relationship between newlywed couples. The observed effects can be thus categorized in four different themes which are Adverse Circumstances; which allows aspects of the partner's lives to change as they put distance between them, Initial Adjustment; which speaks about how both partners in a long distance relationship adjust themselves to the changing attitudes and modes of communication brought about by distance, Connectivity Reinforcements; which deals with how the separated partners maintain the connection between them through various means, and Psychological Outcomes; which deals with the mental aspects that are affected by the separation of the couple. The data was obtained through online interviews with the participants, who have given their informed consent to go with said interview. The results of the interview are taken as findings for the study, and meet the criteria of the previously mentioned themes, and serve as supporting evidence for said themes.

Reasons for conflicts have been experienced as expected from the newlyweds. These reasons mainly consist of foreign situations. Conflicts often causes a divide between partners, which may temporarily damage partners' sense of belonging and closeness to one another (Feeney, 2009; Loving, Le, \& Crockett, 2009; as cited by Keneski, Neff, and Loving, 2017), however, the participants were fortunately able to adjust and positively deal with their problems even with the distance between them. Furthermore, they were able to mend and fortify their relationships as they were willing to make compromises in order to fit their situation. Intimacy, trust, and communication satisfaction were revealed to be the main ingredients of relationship satisfaction in people who are in online relationships (Anderson \& Emmers-Sommer, 2006; England, 2018).

The couples were able to stay in touch with the utilization of online medium such as Facebook Messenger and Whatsapp. The frequency with which different channels of communication were used was linked to relationship and communication satisfaction (Hampton et al., 2017). 
Moreover, the participants have experienced psychological anguish as soon as they lived separately from each other. This can lead to a decrease in a couple's coping abilities and an increase in the likelihood of separation depending on the intensity (Bodenmann and Cina 2006; as cited by Krapf, 2018). Fortunately, they were able to find healthy coping mechanisms to alleviate their distress and loneliness.

Lastly, it is important for the couple to establish some ground rules in order to properly strengthen the relationship. Building intimacy in a relationship is hard, to begin with, but when the emotional gap becomes too wide, people who are in that relationship may start to feel isolated, lost, and confused (Glass, 2020). Therefore, it will be best if both partners involved should spend the first few years together before separating, in case the circumstances won't allow for both to be physically present

Singh (2019) has stated that an increase in the frequency at which long distance couples communicate with each other also contribute to the psychological changes and emotional overhauls as the constant back and forth between the partners, and with the external factors taken into account, can lead to exhaustion for either side. This also supports the experienced psychological anguish long distance couples typically encounter. The recommended action is that couples who are unable to physically stay close together due to certain external factors, such as work, should refrain from communicating on a daily basis and partake in recreational tasks on their end to further mitigate emotional withdrawal and make the times they are able to meet physically all the more better.

For future studies, the researchers recommend for newlywed couples not to engage in long-distance relationships. It is easier to adjust in a physically close environment than to adjust in long-distance relationships right after marriage. For future researchers, it is recommended to have more respondents to have a thorough and precise understanding of the research problem.

\section{Acknowledgements}

The completion of this research study can be credited to a number of people who assisted us in completing it. Deepest gratitude to everyone, especially to the following people:

Dr. Evelyn S. Mariñas, the group's research adviser, for her unwavering patience and determination to guide the group into the completion process of their paper with her knowledge and expertise. This publication of this research study would not be possible without her invaluable advices and suggestions. Moreover, her admirable drive for the perfection of this study gave the researchers the confidence they needed and inspired them to always be the best version of themselves. It would always be an honor to be under her guidance and all the experience they have had with her will serve as their primary guide in life and in their academic careers;

Dr. Alexander S. Acosta, the school's beloved principal, for his genuine enthusiasm in guiding the researchers and his never-ending strive for excellence;

Dr. Noemi F. Formaran, the Senior High School Department's kind-hearted vice principal, for her endless encouragement and support for this study's success;

Maricel T. Gubat, MEd., the loving adviser of 12 - Mercury, for her heartening optimism and especially for being the section's second mother;

Marife M. Perlas-Dimailig, MASEd, Efren L. Burgos, MAT, and Dave B. Buragay, MAEd for their efforts in the validation and betterment of this study;

The teachers of the department for giving their all in imparting knowledge with lessons that can't be easily taught;

The researchers would also like to express their appreciation to their respondents for trusting and opening up to them about their experiences;

Their friends and family for being a great moral support overall; 
Beyond everything, the Almighty God, for bestowing the strength, wisdom, guidance and divine protection to the researchers as they accomplish the study.

\section{References}

6 Untold Personal Growth Benefits from a Long-Distance Relationship. (2021, September 12). The Good Men Project. https://goodmenproject.com/featured-content/6-untold-personal-growth-benefits-froma-long-distance-relationship/

Acedera, K. A., \& Yeoh, B. S. A. (2019). 'Making time': Long-distance marriages and the temporalities of the transnational family. Current Sociology, 67(2), 250-272. http://dx.doi.org/10.1177/0011392118792927

Aspers, P., \& Corte, U. (2019). What is Qualitative in Qualitative Research. Qualitative Sociology, 42(2), 139-160. https://doi.org/10.1007/S11133-019-9413-7

Awonuga, O. (2020). Fostering resilience in long-distance relationships: An application of the theory of resilience and relational load (Order No. 27831221). Available from ProQuest Dissertations \& Theses Global. (2411701068). Retrieved from https://www.proquest.com/dissertationstheses/fostering-resilience-long-distance-relationships/docview/2411701068/se-2?accountid=49936

Baldt, B., \& Sirsch, U. (2020). What happens abroad stays abroad? going on a student exchange while being in a committed relationship. Journal of International Students, 10(1), 1-16. doi:http://dx.doi.org/10.32674/jis.v0i0.1047

Belus, J., et al (2018, April). Staying Connected: An Examination of Relationship Maintenance Behaviors in Long-Distance Relationships. https://www.tandfonline.com/doi/abs/10.1080/01494929.2018.1458004?journalCode=wmfr20

Benyamina, A., Larosab, A. T., Afrac, S. A., \& Handayanid, E. (2019, August). A Qualitative Study of Marital Satisfaction and the Newlyweds of Depok. In 2nd International Conference on Intervention and Applied Psychology (ICIAP 2018) (pp. 179-190). Atlantis Press.

Bratcher, T. (2017). Distance in Relationships as a Moderator of Relationship Characteristics on Relationship Outcomes (Order No. 10686315). Available from ProQuest Dissertations \& Theses Global. (2001861565). https://www.proquest.com/dissertations-theses/distance-relationships-as-moderatorrelationship/docview/2001861565/se-2?accountid=49936

Carmina, G. (2021, August 16). An Easy Tip to Make Your Long-Distance Relationship Work. Medium. Retrieved January 7, 2022, from https://medium.com/hello-love/an-easy-tip-to-make-your-longdistance-relationship-work-7148fad1076f

Carroll, L. (2020, February 14). Love Skills: Media Coverage » Linda Carroll. Linda Carroll. Retrieved December 22, 2021, from https://lindaacarroll.com/love-skills-media-coverage/

Craft, S. A. (2018). Relational Satisfaction among Non-proximal Romantic Relationships Using Adult Attachment Theory. Washington State University.

Crossman, A. (2020, March 19). Purposive Sampling Definition and Types. ThoughtCo. Retrieved December 20, 2021, from https://www.thoughtco.com/purposive-sampling-3026727

Eka Fhitrah, K., \& Afdal, A. (2021, February 5). Marital Quality: Analysis on Couples Who Have LongDistance Marriages, 2(1). 10.24036/005394ijaccs

England, M. (2018). Extreme Long-Distance Relationships and the Role of Idealisation: A Mixed Methods 
Study Exploring the Predictors of Relationship Satisfaction in Extreme Long-Distance Relationships (Order No. 28167271). Available from ProQuest Dissertations \& Theses Global. (2462481172). https://www.proquest.com/dissertations-theses/extreme-long-distance-relationshipsrole/docview/2462481172/se-2?accountid=49936

Engle, G., \& Johnson, L. (2020, May 18). 19 Best Tips to Make a Long Distance Relationship Last. Oprah Daily. Retrieved January 7, 2022, from https://www.oprahdaily.com/life/relationshipslove/a27628635/long-distance-relationship-tips/

Faradina, S., Mawarpury, M., Sari, K., \& Dayo, T. (2020). Self-disclosure in Marriage, 206-212. $10.5220 / 0009441002060212$

Garcia, N. H., \& Acosta, A. S. (2016). From aggressive dealing to progressive leading: A phenomenological impact on proversified leadership skills of Philippine schools overseas (PSOs). PONTE International Scientific Researches Journal, 72(12). 10.21506/j.ponte.2016.12.49

Glass, L. (2020) Coping With An Emotionally Distant Partner, https://www.lovetopivot.com/deal-withemotional-unavailability-partner-stonewalling/

Godana, A. H. (2019). The role of enduring vulnerabilities, stressful life events and adaptive processes in newlyweds marital quality and adjustment (Doctoral dissertation).

Goldsmith, K. M., \& Byers, E. S. (2018). Perceived and reported romantic and sexual outcomes in longdistance and geographically close relationships. The Canadian Journal of Human Sexuality, 27(2), 144-156.

González-Ramos, A. M. (2020). Digital Communication Tools for Fostering Career Advancement and Sustaining Interpersonal Relationships. Sociological Research Online, 25(2), 184-200. https://doi.org/10.1177/1360780419861649

Goodcase, E. T., Nalbone, D. P., Hecker, L. L., \& Latty, C. (2018). The role of attachment anxiety and avoidance in communication modality and relationship quality of romantic relationships initiated online. The American Journal of Family Therapy, 46(2), 168183. https://doi.org/10.1080/01926187.2018.1461032

Hampton, A. J., Rawlings, J., Treger, S., \&; Sprecher, S. (2018). Channels of computer-mediated communication and satisfaction in long-distance relationships. Interpersona: An International Journal on Personal Relationships, 11(2), 171-187. https://doi.org/10.5964/ijpr.v11i2.273

Holtzman, S., Kushlev, K., Wozny, A., \& Godard, R. (2020). Long-distance texting: text messaging predicts relationship satisfaction in long-distance relationships. https://doi.org/10.31234/osf.io/28b93

Irarrázaval, L. (2020). A phenomenological paradigm for empirical research in psychiatry and psychology: Open questions. Frontiers in Psychology, 11, 1. https://doi.org/10.3389/fpsyg.2020.01399

Johari, S., Singh, R., \& Mehra, M. (2020). Differences over Marital Adjustment of Living Apart Together Couples and Proximal Couples. Indian Journal of Extension Education, 56(4), 74-80.

Kansky, J. (2018). What's love got to do with it? Romantic relationships and well-being. Handbook of wellbeing. Salt Lake City, UT: DEF Publishers.

Kelpinski, L. F. (2019). We Can Go the Distance: Communicating Through Conflicts in Long-distance Friendships (Order No. 13902119). Available from ProQuest Dissertations \& Theses Global. (2315539676). https://www.proquest.com/dissertations-theses/we-can-go-distance-communicatingthrough/docview/2315539676/se-2?accountid=49936

Keneski, E., Neff, L. A., \& Loving, T. J. (2018). The importance of a few good friends: Perceived network 
support moderates the association between daily marital conflict and diurnal cortisol. Social Psychological and Personality Science, 9(8), 962-971.

Kibin. (2017). The Main Causes of Long-Distance Relationships. http://www.kibin.com/essay-examples/themain-causes-of-long-distance-relationships-V7iu $4 \mathrm{~g} 10$

Krapf, S. (2018). Moving in or Breaking Up? The Role of Distance in the Development of Romantic Relationships. European Journal of Population, 34(3), 313-336. http://dx.doi.org/10.1007/s10680017-9428-2

Kurniasari, D. A. (2021). The Correlation between Students' Attitude in Online Learning and their English Achievement at MTsN 3 Ponorogo (Doctoral dissertation, IAIN Ponorogo).

Lee, H. (2018). Behind closed windows: A study of long-distance relationships and susceptibility to aggression (Order No. 10824299). Available from ProQuest Dissertations \& Theses Global. (2049664305). Retrieved from https://www.proquest.com/dissertations-theses/behind-closedwindows-study-long-distance/docview/2049664305/se-2?accountid=49936

McLeod, S. A. (2019, July 30). Qualitative vs quantitative research. Simply Psychology. https://www.simplypsychology.org/qualitative-quantitative.html

Monk, J. K., Ogolsky, B. G., Rice, T. M., Dennison, R. P., \& Ogan, M. (2021). The role of family-of-origin environment and discrepancy in conflict behavior on newlywed marital quality. Journal of Social and Personal Relationships, 38(1), 124-147.

Mostowlansky, T., \& Rota, A. (2020, November 29). Emic and etic. The Cambridge Encyclopedia of Anthropology, 1. http://doi.org/10.29164/20emicetic

Niehuis, S., Reifman, A., Feng, D., \& Huston, T. L. (2016). Courtship progression rate and declines in expressed affection early in marriage: A test of the disillusionment model. Journal of Family Issues, 37(8), 1074-1100.

Oxford Languages. (n.d.). Marriage - Google search. Google. https://www.google.com/search?q=marriage\&rlz=1C1RLNS_enQA910QA910\&oq=marria ge\&aqs=chrome.0.69i59j0i433j012j46j69i6013.2648j0j9\&sourceid=chrome\&ie=UTF-8

Philippine School Doha. (2019, August 14). Philippines School Doha. https://psd.sch.qa/

Raheja, S. (2021, June 23). How your family relationships influence you. Top Doctors. Retrieved December 20, 2021, from https://www.topdoctors.co.uk/medical-articles/how-your-family-relationshipsinfluence-you\#

Rajput Nitu, R. (2017). Marital adjustment and happiness. The International Journal of Indian Psychology, 5 (1), 116-123.

Raypole, C., \& Litner, J. (2021, December 14). 25 Best Tips on Making a Long Distance Relationship Work. Healthline. Retrieved January 7, 2022, from https://www.healthline.com/health/long-distancerelationships\#general-tips

Roberta, A. P., Schiavio, A., \& Biasutti, M. (2020). Adaptation and destabilization of interpersonal relationships in sport and music during the covid-19 lockdown. Heliyon, 6(10) doi:http://dx.doi.org/10.1016/j.heliyon.2020.e05212

Sawai, J. P., Juhari, R., Kahar, R., Ismail, Z., \& Sawai, R. P. (2018). Financial strain, financial management practices, marital satisfaction and marital stability among newlyweds. Management \& Accounting Review (MAR), 17(3), 1-16.

Scott, E. (2020, July 13). How to Improve Your Relationship with Effective Communication Skills. Verywell 
Mind. https://www.verywellmind.com/managing-conflict-in-relationships-communication-tips3144967

Singh, R. P. (2019, March 21). Essentials of Long Distance Relationships. https://medium.com/@_ranapratapsingh/essentials-of-long-distance-relationship-54fafed3e8c5

Smith, B. C. (2018). Idealization and Media Choice in LDR Conflict (Order No. 10814452). Available from ProQuest Dissertations \& Theses Global. (2059826483). https://www.proquest.com/dissertationstheses/idealization-media-choice-ldr-conflict/docview/2059826483/se-2?accountid=49936

Sotto-Herrera, P. P. (2018). The Use of Media Technologies in Long-Distance Relationships [Master's thesis]. https://scholarworks.rit.edu/cgi/viewcontent.cgi?article $=11084 \&$ context=theses

SOV \& SKRIV. (2020, November 23). The IMRaD format | Search \& write. Søk \& Skriv. https://sokogskriv.no/en/writing/the-imrad-format.html\#introduction

Stafford, L. (2006). Maintaining Long-Distance and Cross-Residential Relationships. Journal of Communication, 56(3), 630-631. https://www.proquest.com/scholarly-journals/maintaining-longdistance-cross-residential/docview/57645181/se-2?accountid=49936

Stritof, S. (2021, November 19). Why the First Year of Marriage Is So Hard. Verywell Mind. Retrieved December 20, 2021, from https://www.verywellmind.com/setting-marital-stage-first-two-years2300847

Suminar, J. R., \& Kaddi, S. M. (2018). The phenomenon of marriage couples with long-distance relationship. MIMBAR: Jurnal Sosial dan Pembangunan, 34(1), 121129. https://doi.org/10.29313/mimbar.v34i1.3183

Sutrimo, A. (2018, April). Impact of Premarital Coaching (PMC) Intervention using the Psycho-educational Approach on Parenting Self-efficacy of Newly-married Underage Couples: A Narrative Literature Review of Evidence and Feasibility in Indonesia, 15(1), 41-48. https://doi.org/10.16952/pns.2018.15.1.41

Swarthmore. (2021). What is a consent form? Swarthmore College. https://www.swarthmore.edu/institutional-review-board/what-a-consent-form

Tasew, A., S. (2021, April 01). Marital Conflict Among Couples: The Case of Durbete Town, Amhara Region, Ethiopia. Retrieved from https://www.tandfonline.com/doi/full/10.1080/23311908.2021.1903127

The Lasting Crew. (n.d.). Therapists share how to make long distance relationships work. Lasting. https://getlasting.com/long-distance-

relationships\#: :text=Doubts\%2C\%20insecurities\%2C\%20and\%20jealousy\%20can,verbal\%20assu rances $\% 20$ with $\% 20$ one $\% 20$ another

Wei-Chi, C., \& Hassenzahl, M. (2020, May). Technology-mediated relationship maintenance in romantic long-distance relationships: An autoethnographical research through design. Human - Computer Interaction, 35(3), 240-287. doi:http://dx.doi.org/10.1080/07370024.2017.1401927

Wijayanti, Y. T. (2021, January). Long Distance Marriage Couple Communication Pattern during the Covid19 Pandemic. Jurnal ASPIKOM, 6(1), 208-221. doi:http://dx.doi.org/10.24329/aspikom.v6i1.718

Wulan, D. K., \& Chotimah, K. (2017). Peran regulasi emosi dalam kepuasan pernikahan pada pasangan suami istri usia dewasa awal. Jumal Ecopsy, 4(1), 5863.

Yang, L., Neustaedter, C., \& Schiphorst, T. (2017, May). Communicating through a telepresence robot: A study of long distance relationships. In Proceedings of the 2017 CHI Conference Extended 
Abstracts on Human Factors in Computing Systems (pp. 3027-3033).

Yang, X. (2021). Port-all: Reproduction of the sense of companionship in a long-distance relationship (Order No. 28498856). Available from ProQuest Dissertations \& Theses Global. (2542365472). Retrieved from https://www.proquest.com/dissertations-theses/port-all-reproduction-sense-companionshiplong/docview/2542365472/se-2?accountid=49936 


\section{Biographical Sketch}

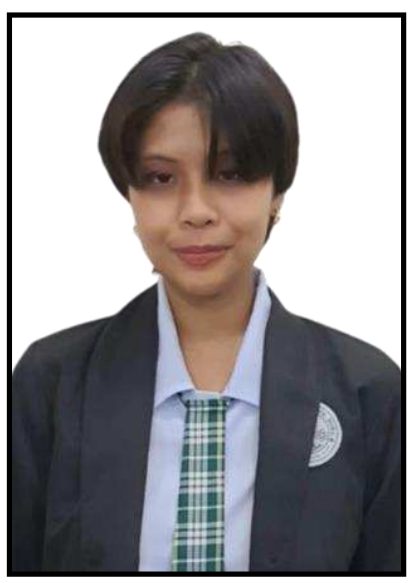

Hildegard Anne S. Alimurong, born on April 27, 2004, is the eldest child of Humphrey and Abelia Alimurong. She is a grade 12 STEM (Science, Technology, Engineering, and Mathematics) student in Philippine School Doha. As a consistent honor student since Preschool, she always aims for perfection in everything. One of her fondest academic memories are being awarded Best in English CEM way back in 2013, securing the 1st rank in her section in grade 7 and 10, having to participate in the Research Congress 2020 along with her former research groupmates, and being a Laureolan. Moreover, her adoration towards arts motivated her to join various art competitions such as the Science E-Banner Making, Science Assemblage, ASEAN Infoboard Making, Buwan ng Wika Poster Making, and the Junior Dance Club in her junior years and is currently a layout artist in The LINK, the journalist organization of the school. As someone who possesses a curious mind, she had always aspired to be involved in the field of either Forensics or Psychology. Her free-spiritedness will always drive herself to seek the thrills and serenity of life.
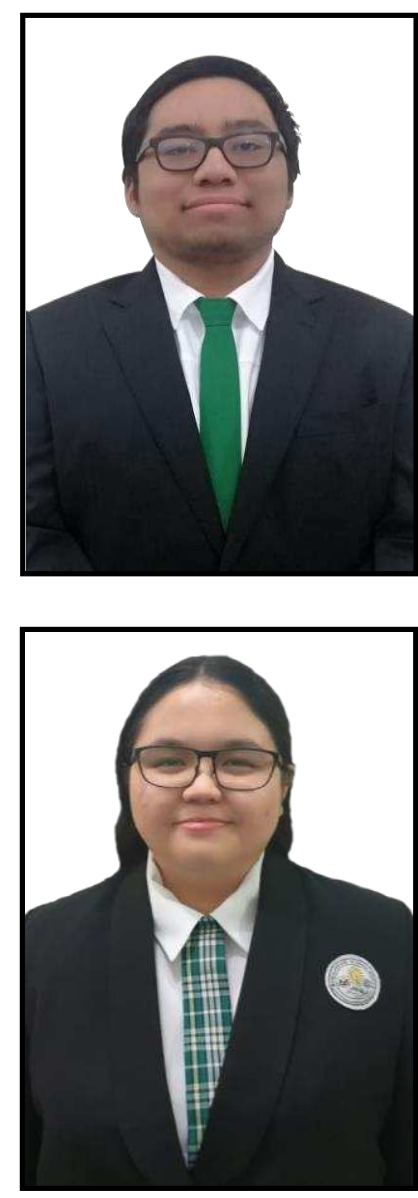

Gavin Mysjah C. Villegas is a 17-year-old teenager, born on the 30th of June 2004 in Marikina City, Metro Manila, Philippines. Son of Marlon 0. Villegas and Girlie C. Villegas, and older brother to Misjah Gynelle C. Villegas and Gustav Miscah C. Villegas. He is a Grade 12 STEM student at Philippine School Doha. His hobbies consist of drawing, listening to music, reading, and occasionally watching movies. He strives to be a graphic designer or animator in the future.

Gwyn Steffany G. Maningo, born on April 25, 2003 in Carmen, Cebu in the Philippines. Currently, she is a grade 12 student in the STEM (Science, Technology, Engineering, and Mathematics) course at The Philippines School Doha. From Kindergarten to the current grade, she has been a consistent honor student from previous schools (Philippine Women's College of Davao, The Philippine School Dubai, Ateneo de Davao). She excels in computer programming and enjoys anything with computers and science. 


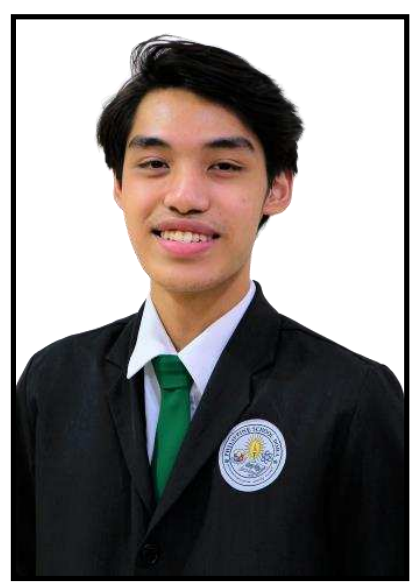

Seth Zackari P. Balde was born on the 9th of September, 2003; in the Philippine provincial town of Legazpi City, Albay. He is a consistent honor student and bronze awardee throughout his 15 years of schooling at Philippine School Doha, securing a final rank of 2 nd in his class during Grades 2, 3, 6, 8, 9, and 11. As an aspiring biomedical researcher, his determination to achieve such aspiration is shown as he excels in his math and science subjects - including a CEM award for both Math and Science (2014 \& 2018). He also joined several extracurricular activities and competitions related to these fields; Such as the PICE Math and Science Quiz Bee (2019 \& 2021), SDG Infomercial Making Competition (2019), and the Research Congress 2020. Moreover, he also excels in his art skills which led him to join the school paper organization, The LINK, under the layouts department. His skills in art also landed him on winning places in art competitions. Such as winning 2nd places in the Buwan ng Wika poster making, the Science Eco-Poster making, the Science E-Banner making, and 1st in the ASEAN infomercial making, and the school's Celebration of Learning Logo making contest. He believes that research and discovery keep the world turning, thus he always keeps an open and curious mind to find any opportunity that contributes to the development of knowledge and understanding of our anthropocene.

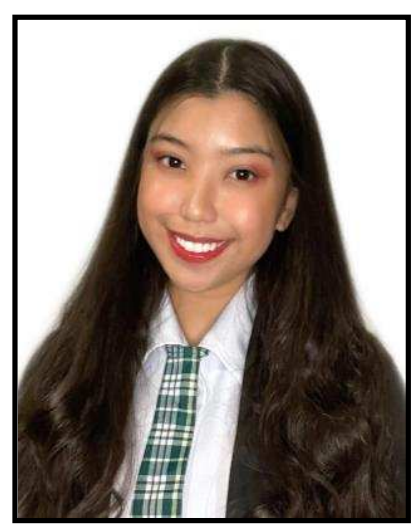

Ramella Glen G. Dinglasan was born in Bauan, Batangas on July 8th of 2004. She is a grade 12 STEM student of Philippine School Doha. In her 17 years of existence and counting, she acquired skills and talents that displayed her personality and perseverance. These attributes were developed as she joined multiple competitions, such as Eco-Fashion, Character Impersonation, Ultimate Dance Battle, and Dance Sports throughout high school. Being a consistent top 10 throughout Junior High School, a Bronze Awardee, and a semestral Laureola Bronze Awardee became her way of gratitude towards her parents. Furthermore, she pursued joining the Theater Club and HIYAW dance troupe to grow and expand her knowledge about performing. A passion for art was soon discovered and was applied to her chosen course. Architecture always amused her with its variety of designs and numerous possibilities. One of her goals is to become a licensed Architect and advocate on sustainability development for the next generation. 


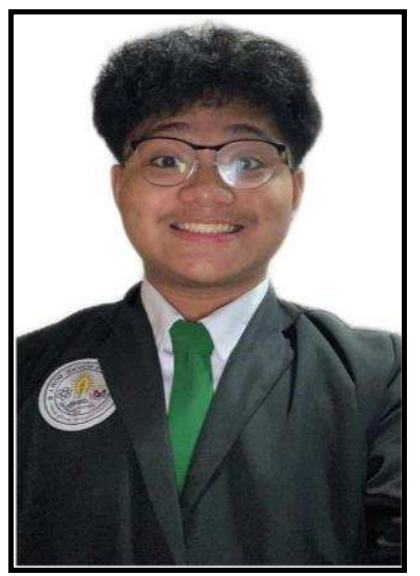

Gerone Philip E. Escobedo, born in Cebu City, Cebu on February 12, 2004. He is a 12 STEM student of Philippine School Doha. A consistent top honor student during his primary and intermediate schooling in an International School in Doha, Qatar. Has been consistent in achieving the highest grade in the class of Computer System Servicing subject throughout his JHS. Was a Senior and Officer in the Robotics Club offered by school. Joined multiple basketball sporting events hosted by the school and off campus, including the summer basketball program. Was accepted and part of the Philippine School Doha U19 Basketball Varsity Team S.Y. 2019-2020. 